\section{All For One, One For All}

James J. James, MD, DrPH, MHA
$\mathrm{T}$ he journal, Disaster Medicine and Public Health Preparedness, is thrilled to be able to present the collection of articles on health care coalitions in this issue. Some of the articles (Priest) are grounded in traditional methodology, whereas others range from opinion through serious policy analysis (Dornauer). The authors and Guest Editors represent the recognized leaders in the field of preparedness and response (Benjamin, Lurie, Vanderwagen) and come from the many diverse backgrounds necessary to the formation of effective health care coalitions under the Hospital Preparedness Program. The additional material in this issue was selected to complement and enhance this special collection. In all, the articles provide a rich kaleidoscope of data, information, analysis, and opinion that will serve as the basis for the additional, more rigid, work required to truly evolve health care coalitions into well recognized and formidable entities.

As such, I will not utilize limited editorial space to repeat what is better expressed by the experts in the field but to briefly comment on the development of health care coalitions from an evolutionary perspective beginning with efforts in the post-9/11 era. Interestingly, in my view, this evolution is roughly reflected in the timeless observation of Henry Ford:

Coming together is a beginning;

Keeping together is progress;

Working together is success.

Following 9/11 up to the time of Hurricane Katrina, countless meetings and conferences spawned good ideas and intentions that were all too often unachieved because they remained disconnected without a uniform infrastructure or system. Interestingly, at the time, many health care providers and institutions were advised to prepare for a single case of a potential agent such as anthrax as an initial step in achieving preparedness.
The inherent weakness of this state of affairs was tragically demonstrated in the uncoordinated, often dysfunctional, response to Hurricane Katrina in August 2005.

Many changes in preparedness and response resulted from the many official reviews of this disaster, most notably in the Pandemic and All-Hazards Preparedness Act (December 2006) and the creation of the Office of the Assistant Secretary for Preparedness and Response (ASPR). This office, more than any other, provided the skeletal infrastructure needed to enable some degree of continuity and cohesion for those individuals and entities focused on preparedness and response activities. If these often competing participants were not always successful at truly working together, they were able to represent the necessary elements to develop a preparedness and response system. Unfortunately, and mainly due to individual and organizational competitiveness within both the government and nongovernment sectors, efforts tended to be expended within single agencies and organizations but still suffered from the lack of an overall "population good" systemic perspective.

This was well recognized within the office of ASPR, and subsequent efforts to address this deficiency resulted in the support and growth of health care coalitions that brought together the essential components of preparedness and response with a common goal of providing the necessary response capability to improve health outcomes in disaster. This provides the milieu for success: "working together." It is all too well recognized that an essential component of effective preparedness and response is systematic integration across all sectors and disciplines; health care coalitions provide the framework for achieving this. 